Article

\title{
Exploring the benefits of photovoltaic non-optimal orientations in buildings
}

\author{
Esteban Sánchez 1,* , Ángel José Ordóñez ${ }^{2}$, Alberto Sánchez ${ }^{3}$, Raúl García ${ }^{4}$ and Javier Parra-Domínguez ${ }^{5}$ \\ 1 Escuela Técnica Superior de Ingeniería Industrial, Universidad de Salamanca, Avda. Fernando Ballesteros, \\ 2, Béjar, 37700, (Salamanca) España, esh@usal.es \\ 2 Escuela Técnica Superior de Ingeniería Industrial, Universidad de Salamanca, Avda. Fernando Ballesteros, \\ 2, Béjar, 37700, (Salamanca) España, aordonez@usal.es \\ 3 Escuela Técnica Superior de Ingeniería Industrial, Universidad de Salamanca, Avda. Fernando Ballesteros, \\ 2, Béjar, 37700, (Salamanca) España, aspatrocinio@usal.es \\ 3 Escuela Técnica Superior de Ingeniería Industrial, Universidad de Salamanca, Avda. Fernando Ballesteros, \\ 2, Béjar, 37700, (Salamanca) España, raulovej@usal.es \\ 3 Escuela Técnica Superior de Ingeniería Industrial, Universidad de Salamanca, Avda. Fernando Ballesteros, \\ 2, Béjar, 37700, (Salamanca) España, javierparra@usal.es \\ * Correspondence: esh@usal.es; Tel.: 34-923 408080.
}

\begin{abstract}
As Solar Photovoltaics in buildings reaches maturity, grid integration and economic yield are topics of greater interest. Some strategies like demand shift management or storing electricity in batteries are proposed to reach a higher share of PV into the distribution grid. The price reduction of solar PV has driven a change in support policies from the feed-in tariff to net metering and, nowadays, to net billing schemes. With an increase in PV installations, aesthetical aspects are more valued, and coplanar placement of modules is preferred. By analyzing the operation of two PV installations: one residential and another industrial, we will show that smart use of these non-optimal orientations for the yearly production can be more convenient. Through the economic evaluation of several PV orientations, it is found that the economic performance could minimize the energy loss from optimal. The analysis of different alternatives for each study case has allowed us to identify several benefits for these orientations.
\end{abstract}

Keywords: Solar Photovoltaics; Self-consumption; Grid-integration, Curtailment, Buildings, BIPV.

\section{Introduction}

The growth that the population, the economy, and living standards have is generating a continuous increase in energy demand; it is expected that this growth will be approximately between 1.5 and 3 times more by 2050 [1,2]. To meet this demand, renewable energies are presented as a viable alternative, [3] estimates that by 2050, the amount of oil and coal in the energy mix will have been reduced to more than half from current levels, and the energy supply mix It will be divided equally between renewable and non-renewable sources.

According to the latest report from the International Energy Agency [4], the share of renewable energies in electricity generation is expected to increase to almost $30 \%$ in 2021, its highest share since the beginning of the Industrial Revolution, where solar energy PV and wind will contribute approximately two-thirds of this growth. The great progress of solar energy is mainly due to the increase in its efficiency and the continuous reduction of costs [5]. This has allowed the installed photovoltaic solar capacity to go from $580 \mathrm{GW}$ in 2019 to 707 GW in 2020 [6], presenting an increase of approximately 22\%. The European landscape has a similar trend, according to the reported prospect of EU market of 
"SolarPower Europe" has been incorporated 16.7 GW of new photovoltaic installations in 2019, an increase of 104\% compared to $8.2 \mathrm{GW}$ of 2018 [7], installing more new solar capacity than any other power generation technology [8].

Several studies have focused on issues of economic viability, efficiency, and applications of photovoltaic technologies [9-12]. In general, the photovoltaic systems that are mostly connected to the network [13] present several economic benefits [14] and also have a satisfactory social acceptance, as indicated in the research of $[15,16]$.

In recent years the manufacture of photovoltaic solar cells and photovoltaic modules has largely advanced [17], and its implementation in buildings is increasingly accepted. There are two main ways to incorporate photovoltaic into a building, BAPV (photovoltaic applied to the building) and BIPV (photovoltaic integrated into the building). In BAPV systems, photovoltaic modules are installed on the building's facade; in BIPV systems, photovoltaic modules are part of the building's structure [18]; that is, they serve as construction material in the envelope as multifunctional elements [19].

BIPV is considered one of the four essential key factors for the future success of PV, as detailed in [20]. The power generation efficiency of the BIPV system is lower compared to standalone photovoltaic systems and compared to BIPV/T (Building Integrated Photovoltaic Thermal). Still, it eliminates the additional space required for power generation and presents better aesthetics for the building structure [19].

An analysis by [21] showed that in $2 \mathrm{~km}^{2}$ of the urban area, the facades of the buildings provide almost three times with the area of the roofs of the buildings; however, due to the non-optimal inclination and orientation, they receive only $41 \%$ of the total irradiation. This is complemented by the research of [22] that, through a simulation with LiDAR data, obtained that the average annual irradiation per unit area on the facades is lower than that of the roofs, but that the much larger area means that a significant amount of energy reaches the vertical facades throughout the year. Confirming that the annual irradiation in the vertical facades is lower than that of the most favourable surfaces such as roofs, but given that their coverage areas are huge, the solar potential of the facades is "relevant" for the general solar potential of a building and/or an urban area.

A building with BAPV or BIPV reaches grid parity when photovoltaic electricity costs are equal to the retail electricity price, taking into account income, savings, implementation costs, maintenance costs, tax and depreciation [23]. Additionally, there is the influence of non-technical and uncontrollable factors that complicate reaching grid parity, such as investment costs, credit discount rate, and variation in the electricity market cost, among others, which poses a scenario that requires economic incentives and supportive policies $[23,24]$.

In some mature solar markets such as Germany and Italy, the low costs of SFV implementation, low discount rates, and high retail electricity prices have allowed reaching grid parity [25,26]. In the case of Germany, until 2012, there was a special bonus for selfconsumed electricity. Still, when the FiT fell below the retail price of electricity, this bonus disappeared, establishing profitable self-consumption without additional incentives $[27,28]$.

In most countries with self-consumption regulations, there are two main ways to compensate for the energy supplied to the electricity grid by the SFVs: net metering and 
net billing. Net metering is used to offset the photovoltaic production over a longer period of time against consumption; the production can be "stored" in the electricity grid and increase self-consumption; for example, the surplus during the summer months can be saved for the winter months [27]. In the net billing scheme, the energy fed into the grid is paid at a lower rate than the retail rate and can relate to the rate of the pool [29]. In [30] is performed a detailed comparison of the differences between net metering and net billing.

In Spain, the recent approval of Royal Decree 244/2019 [31] made it possible to regulate the administrative, technical and economic conditions of Royal Decree-Law 15/2018 [32]. The new legislation introduces a simplified compensation mechanism to electricity bills for consumers, offsetting their surplus of self-produced but not self-consumed energy [33]. The main changes in current regulations are:

- Energy produced from self-consumption facilities is completely tax-free. With this, the well-known "sun tax" is permanently eliminated.

- The right to "collective self-consumption" is recognized.

- Administrative and technical procedures are simplified, especially for small power installations.

- The power limit is eliminated. Previously, you could install a photovoltaic power equal to or less than contracted.

- It is possible to rent roofs and/or covers so that third parties can produce electricity.

Based on this new Spanish legislation, it is important to consider the functionality of the BIPV systems and their implementation in the medium term to guarantee the construction of "Zero Energy Buildings". A study carried out by [34] found that an internal rate of return of rooftop BIPV systems can be obtained in three countries above $80 \%$ : $\mathrm{Cy}$ prus, Portugal, and Spain, which also present high values of solar irradiance.

Regardless of the photovoltaic strategy selected, the analysis carried out by [35] indicates through the description of some examples that there is a limit in the amount of energy that a photovoltaic collector can generate per square meter. This amount depends mainly on the efficiency photovoltaic, inclination and azimuth angles of the PV generator, latitude and efficiency of the balance of the system.

Taking these considerations, the main strategy photovoltaic self-consumption systems (PVSC hereinafter) is to increase the consumption of self-produced electricity by placing photovoltaic modules in a suitable façade; for example, [35] showed that the photovoltaic modules installed on a façade facing west adjust to residential applications, where electricity consumption tends to peak in the afternoon. For buildings for administrative or office uses, a facility southeast provides a better fit for electricity consumption, which is higher in the morning [36]. This presents us with scenarios where installing solar panels in non-optimal orientations is possible to obtain a potential benefit. These scenarios would produce lower amounts of energy, but their hourly production profiles could shift beyond noon, allowing them to better meet demand [37].

The main objective of this research is to analyze the technical and economic potential of the integration of PVSC in non-optimal orientations in Spain. For this, the analysis of two case studies is carried out on a residential PVSC and an industrial PVSC. Based on one full year of real operational data for the residential PVSC, the operation of several PV arrangements with different orientations will be simulated and extensive energy and economic analysis will be done considering present and future residential tariffs in Spain. In 
a similar fashion study of an industrial PVSC will be done, comparing different configurations.

This document is divided into four sections. After the Introduction, Section 2 describes the case studies, with a brief description of Spanish residential tariffs and methods used in the analysis of energy consumption and photovoltaic production for each case study. The results are presented in Section 3, with an extensive economic analysis for the different configurations evaluated in the residential PVSC and considering the actual and future residential tariffs. In Section 4 their discussion is carried out and the conclusions are presented. The main findings of our study include the fair economic performance of non-optimal orientations despite their lower energy production and the positive impact of the new electricity tariffs in Spain for PVSC economic performance.

\section{Materials and Methods}

This work is based on two PVSC installations, a residential one and an industrial one. For the residential PVSC there is a full-year dataset, so it is possible to carry out a complete energy and economic analysis for alternative PV configurations. For the industrial PVSC there are data for some months so the analysis will describe the design process for selecting the more convenient configuration for the modules in this case.

\subsection{Case study \#1: Residential PVSC}

The residential PVSC is a single-home building located in the Madrid metropolitan area. It is a two-stories detached building equipped with HVAC, shown in Figure 1. The climate in Madrid is the continental-mediterranean, with cold winter and hot summer. Hence, the yearly consumption is high, $14,189 \mathrm{kWh}$ for the full year under study. The installation has a peak power of 3.85kW and uses 10 Canadian Solar Ku Max CS3U-385MS monocrystalline PERC PV modules with power optimizers and a 4kW inverter SolarEdge. The modules are installed in the roof, with a southeast orientation in parallel with the walls and an inclination of $30^{\circ}$.

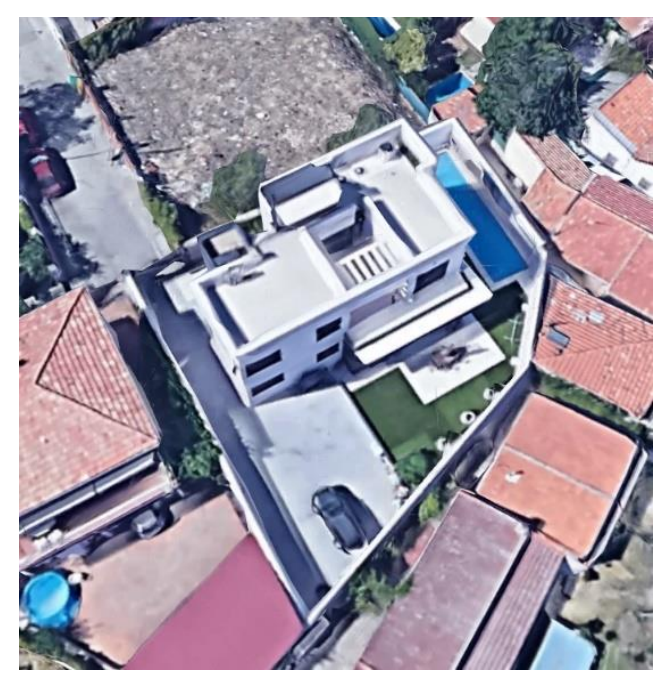

Figure 1. Residential building under study before PV installation.

The PVSC was installed in February 2020, so there are data for full months starting in March 2020. The monitoring system provides data of PV production, electricity 
consumed and interchanged with the grid every fifteen minutes. As a summary, the energy produced was $6,010 \mathrm{kWh}, 3,293 \mathrm{kWh}$ where self-consumed and $2,717 \mathrm{kWh}$ were feed into the grid. The self-consumption degree was of $55 \%$, and the self-sufficiency degree was of $23 \%$.

These data will serve as a reference for comparison with simulations of alternative installations with the modules placed in different orientations. The simulations are performed using PVSYST software. Regarding the electricity prices, the Spanish electrical grid operator REE provides real-time information about electricity pricing and valuation of surplus electricity for PVSC plants in its webpage ESIOS [38]. With the processed data, it is possible to compute the economic savings under Spanish self-consumption regulation [31] and residential pricing of electricity, which will be addressed in the next subsection.

\subsubsection{Residential tariffs in Spain}

The electrical tariffs in Spain are in the process of change to a new structure and are briefly exposed. Currently, there are three tariffs of choice in the regulated market or PVPC (voluntary price for the small consumer).

- Time constant tariff: the price of electricity is indexed to the pool market by a fixed toll that includes part of the electrical system costs and is added to the hourly pool market price and other costs, including commercial profit.

- Two-period tariffs: the price of electricity is indexed to the pool market, but the toll has two different values depending on the hour of the day. There are the former 2.0DHA and the 2.0VE for electric vehicles.

The new tariff 2.0TD is a new three-period structure with three periods for the toll according to the whole Spanish electrical system [39]. The final energy cost includes the toll, hourly pool market price, other costs, and commercial profit, as current 2.0DHA tariff. All tariffs are summarized in Table 1. The new electrical tariffs in Spain are expected to be introduced in June 2021 and is intended to fix higher prices on periods of higher consumption to promote demand shift management habits in the customers. In Figure 2 are plotted the demand profiles for the whole Spanish electrical system in representative days of winter and spring and it is clear the selection of peak periods in accordance with the two periods of maximum electricity demand in the Spanish electrical system.

Table 1. Hourly distribution and comparison with solar irradiation for tariff 2.0.

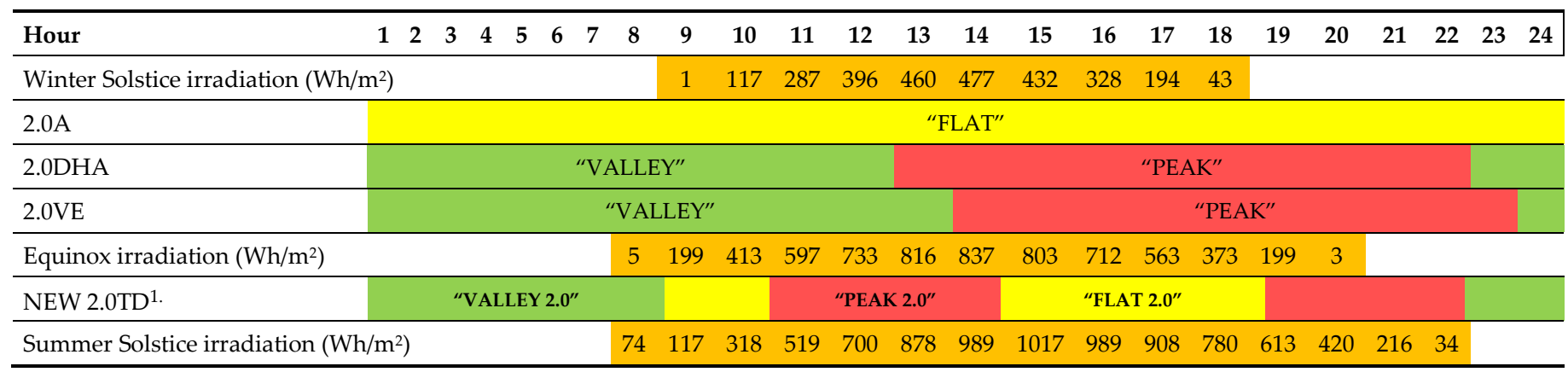

1."Valley" on weekends and public holidays. 


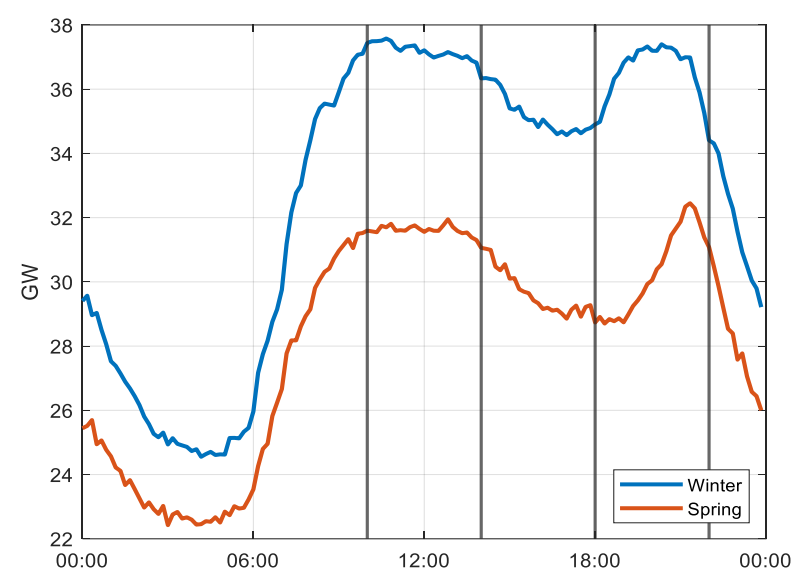

Figure 2. Load profile of Spanish electrical system on representative days. Vertical lines point out the two "peak" periods in tariff 2.0TD corresponding to peak periods in electricity demand.

With the data from the monitoring system, the hourly economic balances are calculated using the prices of electricity published by the Spanish electrical grid operator. The hourly prices for the new tariff 2.0TD are calculated accordingly to the current and future tolls. The results are presented in Table 2 and show a higher economic saving for the PV self-consumed electricity due to the higher electricity prices from 10 a.m. to 2 p.m.

Table 1. Economic performance of the PVSC installation for a full year with the actual tariffs 2.0A and 2.0DHA and with the new 2.0TD tariff.

\begin{tabular}{ccc}
\hline Tariff & Item & Value \\
\hline \multirow{2}{*}{$2.0 \mathrm{~A}$} & Savings & $308.9 €$ \\
& Buy & $-1,126.9 €$ \\
$2.0 \mathrm{DHA}$ & Savings & $267.9 €$ \\
& Buy & $-796.3 €$ \\
$2.0 \mathrm{TD}$ & Savings & $371.5 €$ \\
& Buy & $-1,046.0 €$ \\
& Surplus Compensation ${ }^{1}$ & $84.56 €$ \\
\hline
\end{tabular}

${ }^{1}$ The surplus energy is valuated according to the hourly price published by the Spanish grid operator and discounted in the monthly bill.

\subsection{Case study \#2: Industrial PVSC}

The second case under study is an industrial PVSC for a meat-processing plant in Guijuelo (province of Salamanca). This installation has a peak power of $169 \mathrm{~kW}$. It comprises 386 Canadian Solar CS3W-440MS PERC 440W modules with 193 power optimizers and two $82.5 \mathrm{~kW}$ three-phase Solar Edge inverters for a maximum active power of $165 \mathrm{~kW}$, as is shown in Figure 3. The estimated yearly production is 270MWh with a specific yield of $1597 \mathrm{kWh} / \mathrm{kWp}$ and a performance ratio of $82 \%$. This PVSC corresponds to a factory expansion, with a new building using a flat roof. During the design stage of this plant, several layouts were considered and the main results from PVSYST simulations are presented in Table2.

Table 2. Summary of configurations for PVSC industrial plant 


\begin{tabular}{|c|c|c|c|c|}
\hline South & 336 & $148 \mathrm{~kW}$ & 248MWh & 1675 \\
\hline $\begin{array}{l}\text { Two orientations aligned } \\
\text { with the building }\end{array}$ & 386 & $169 \mathrm{~kW}$ & 270MWh & 1597 \\
\hline East-West & 280 & $123 \mathrm{~kW}$ & 184MWh & 1495 \\
\hline
\end{tabular}

${ }^{1}$ Modules inclination is $15^{\circ}$ in all configurations.

The yearly electricity consumption for the factory was of 665MWh before the expansion, so the owners wanted to accommodate as much PV power as possible. In our case, the yearly production is very similar for the south and two orientations alternatives, and significantly lower for the east-west orientation. It is important to note that due to the high winds present in winter, modules must be placed in landscape orientation and with a low inclination of $15^{\circ}$, so the South orientation is not the optimal production one.

One of the reasons to discard the south orientation was due to the study of consumption patterns and considering the Spanish regulation. This regulation allows a fast-permitting process for PVSC without surplus for installations of nominal power above $100 \mathrm{~kW}$. For installations with a surplus, there is mandatory to obtain permits for grid connection and several steps that delay the process before and after building the PVSC installation. On the other side, the biggest portion of energy consumption is the cooling inherent to the meat-processing. Moreover, the energy consumption in summer doubles that of in winter. In this way, the first option (south orientation) was discarded because it yields a maximum at solar noon, so there is the risk of frequently producing more electricity than consumed, so the inverters crop the production. For non-optimal orientations, the daily production presents a lower peak around midday and produces electricity during more hours in spring and summer.

Finally, the two-orientations option was selected because it was more convenient for easing the installation process and maintenance, as it is shown in Figure 3. Due to the orientation of the building, both the South and East-West orientations generate a sawtooth pattern in the borders resulting in a poor occupancy of the roof and compromising the clearance distance with the external fence. The east-west layout had a particularly difficult access to all points in the plant. This plant is in operation since October 2020, so there are not enough data for a full-year analysis, and the comparison will be made using available data. 


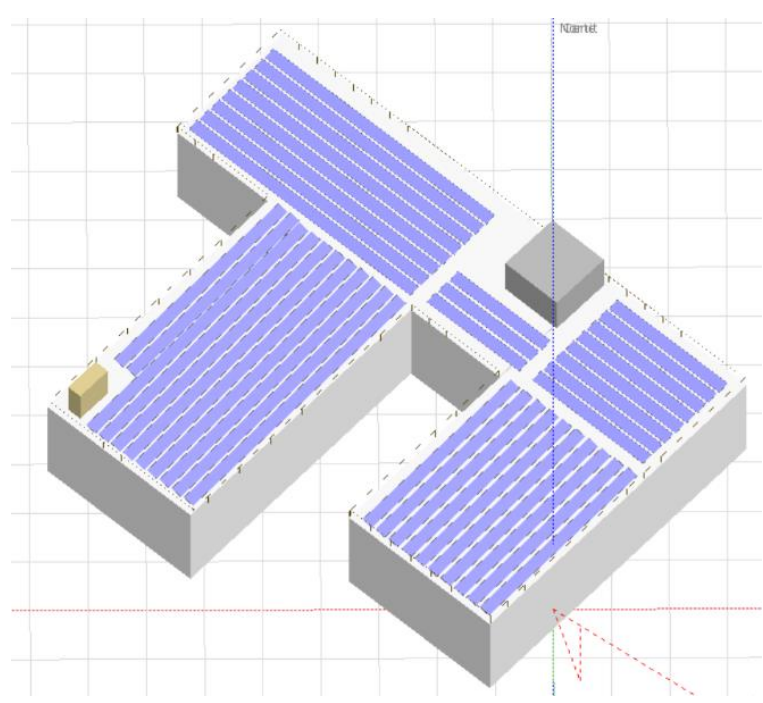

(a)

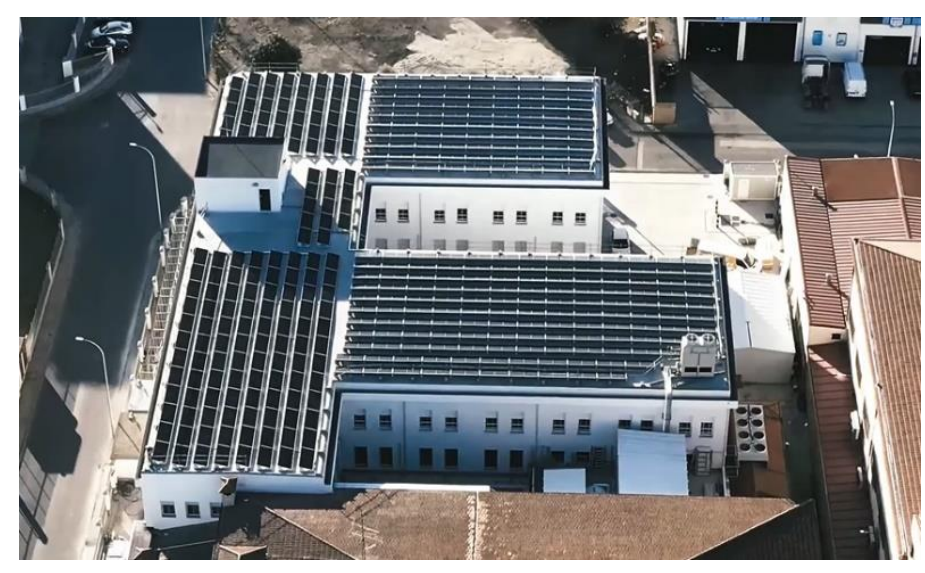

(b)

Figure 3. Industrial PVSC plant (a) PVSYST Model, view from the South (b) Photograph of the plant under construction, view from the North.

\section{Results}

\subsection{Residential PVSC}

Figure 4 shows the behaviour of the building and the PVSC using heatmaps. Figure 4 (a) represents the hourly consumption profile of the home. It can be observed that there are two usual patterns: in the summertime, the air conditioning is connected in the morning and the rest of the year in the afternoon. Exceptions are in spring, with moderate consumption all day, and in some weeks in winter, there is very high consumption due to the colder weather. In Figure 4 (b) the PV production is represented and can be seen that it fits well with the peak consumption in winter but in summer the peak consumption is in the morning.

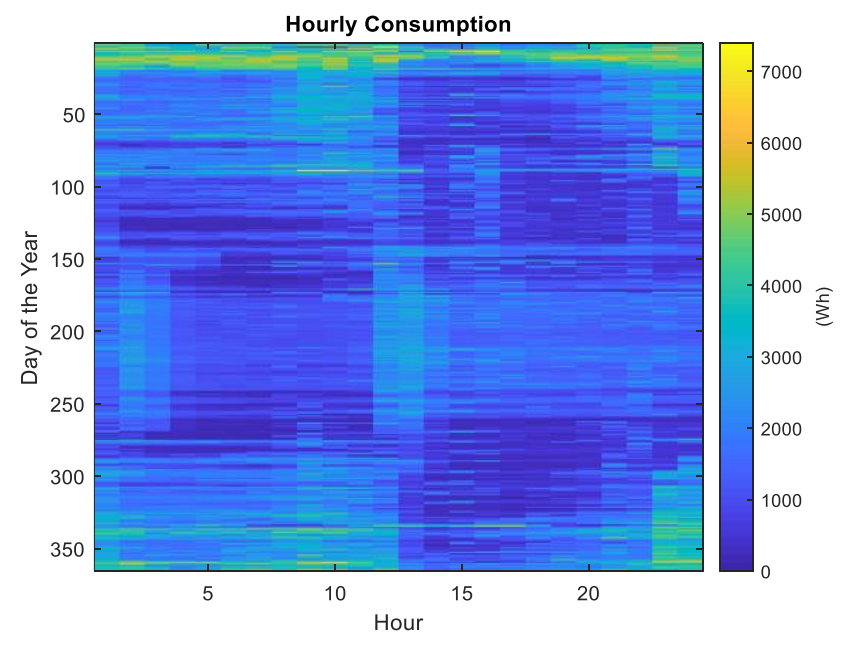

(a)

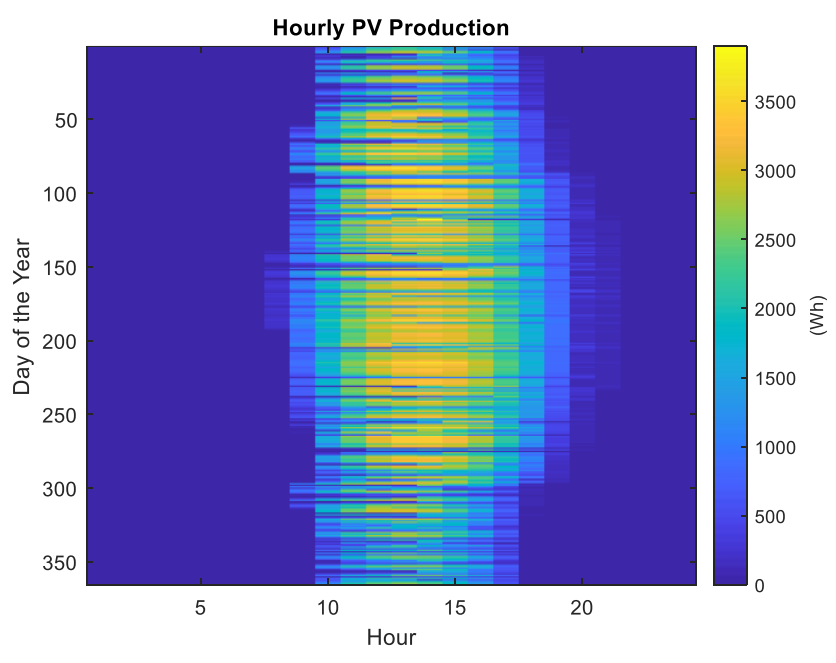

(b)

Figure 4. Heatmap of hourly consumption (a) and production (b). 
This PVSC is built in a single-home detached building with no important shadings from nearby constructions. There are several options for installing a PVSC on it. The orientation is $30^{\circ} \mathrm{E}$ for the larger façade and $60^{\circ} \mathrm{W}$ for the shorter one. The roof is flat and is divided into two sections connected through a corridor. The owners decided to install the PV modules on the southern part of the roof in two rows of 5 modules with portrait orientation, as is shown in Figure 5(a). For this study, we will consider two main alternatives, the first one using shades with an inclination of $30^{\circ}$ on the southeast and southwest façades Figure 5(b), and the second one using modules placed over the same façades Fig $5(\mathrm{c})$.

The original PVSC uses power optimizers (one for each PV module), and they are connected to the inverter in a single string configuration. For the other options is also possible to a single string configuration, but two strings are preferred. In this case, a minimum length of 6 modules is mandatory for this inverter and power optimizers. It is important to note that the two orientations peak power is shifted so that the inverter can easily accommodate the sum of both strings. These inverters can drive a peak power (DC) up to $50 \%$ higher than the nominal AC output. Thus, the cost of the alternatives using several orientations is only increased by the additional modules needed.

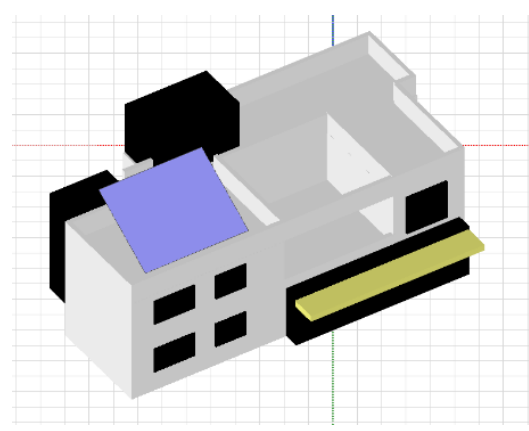

(a)

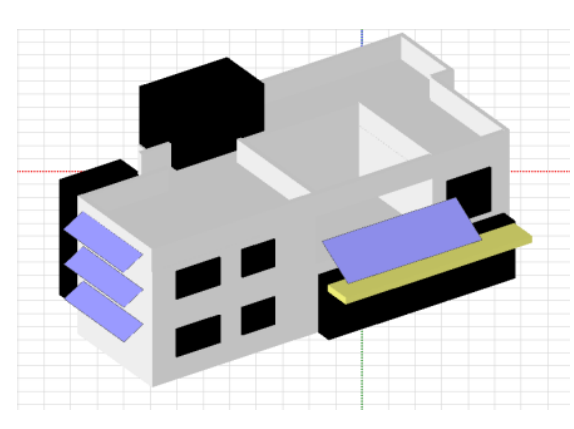

(b)

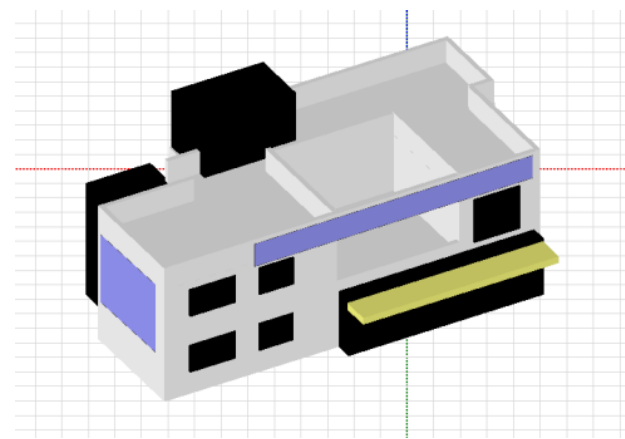

(c)

Figure 5. Residential PVSC plant PVSYST Models (a) Original layout (b) Design using canopies (c) Design using modules attached to the façade.

\subsubsection{Energy analysis}

The different configurations are simulated in PVSYST and compared with the real data from the PVSC. Also, individual orientations for canopies and coplanar modules are simulated to quantify the yield of each orientation. The results are summarized in Table 3 , where all results are from simulations except the real data from the original configuration. The difference between the simulation and the real data is less than $3 \%$ for the original configuration. This is a fair result considering the natural variability of yearly irradiance. The yearly optimum is only $6 \%$ better than the original installation. Still, for the configurations over the façades, the results range from a $10 \%$ less yield for the configuration using canopies and a 33\% less for the configurations with coplanar modules attached to the façades. Due to the orientation of the building, better results are expected for the SE façade. This is confirmed in the simulation of individual façades, but interestingly, for the SE canopy, the yield is only $3 \%$ less than the original, due to the lower inclination and 
shading from the building in the afternoon. The SW canopy yield is $17 \%$ less than the reference; this is not only due to the less favorable orientation, but also due to mutual shading in this particular configuration. For the coplanar modules, there is little difference between both façades.

Table 3. Energy yield of the different configurations for the PVSC.

\begin{tabular}{ccccc}
\hline Configuration & \# Modules PV Power (W) & Yield (kWh/kWp) & $\Delta$ Yield $^{1}$ \\
\hline Original (Real Data) & 10 & 3850 & 1561 & $-3 \%$ \\
Original & 10 & 3850 & 1611 & $0 \%$ \\
Yearly optimum & 10 & 3850 & 1710 & $6 \%$ \\
Canopy (SE \& SW) & 12 & 4620 & 1446 & $-10 \%$ \\
Canopy (SE) & 6 & 2310 & 1558 & $-3 \%$ \\
Canopy (SW) & 6 & 2310 & 1331 & $-17 \%$ \\
Coplanar on façade (SE \& SW) & 12 & 4620 & 1087 & $-33 \%$ \\
Façade (SE) & 6 & 2310 & 1103 & $-32 \%$ \\
Façade (SW) & 6 & 2310 & 1059 & $-34 \%$ \\
Canopy \& Façade (SE) \& (SW) & 12 & 4620 & 1318 & $-18 \%$ \\
\hline
\end{tabular}

${ }^{1}$ Refereed to the original configuration.

The next step is studying the interaction with the building electrical loads and with the electrical grid. The hourly data from simulations is processed with the hourly energy consumption profile, and there are calculated the PV energy self-consumed, and the surplus energy fed into the grid. In additions, the self-consumption and self-sufficiency degrees are calculated as defined in [27] and expressed in equations (1) and (2).

$$
S C D=\text { Self }- \text { consumption }=\frac{E_{P V}-E_{\text {srpl }}}{E_{P V}}
$$

$E_{P V}, P V$ produced energy; $E_{\text {srpl }}, P V$ energy fed into the grid.

$$
\begin{gathered}
S S D=\text { Self }- \text { sufficiency }=\frac{E_{P V}-E_{\text {srpl }}}{E_{\text {in }}+E_{P V}-E_{\text {srpl }}} \\
E_{\text {in }}, \text { energy imported from the grid }
\end{gathered}
$$

The results are presented in Table 4, and there are no big differences between configurations. The configuration coplanar with the façade has a better self-consumption degree that can be explained because of the lower energy production, which translates into lower surplus. The same situation is for the individual orientations so that there are not shown in this table.

Table 4. Energy performance with the building and the grid of the different configurations for the PVSC.

\begin{tabular}{cccccccc}
\hline Configuration & $\begin{array}{c}\text { PV } \\
\text { Produc- } \\
\text { tion }^{1}\end{array}$ & $\begin{array}{c}\text { Energy } \\
\text { Consump- } \\
\text { tion }^{1}\end{array}$ & $\begin{array}{c}\text { PV Self- } \\
\text { Consump- } \\
\text { tion }{ }^{1}\end{array}$ & $\begin{array}{c}\text { Surplus } \\
\text { Energy }\end{array}$ & $\begin{array}{c}\text { Energy } \\
\text { from the } \\
\text { Grid }^{1}\end{array}$ & SCD $^{2}$ SSD $^{3}$ \\
\hline Original (Real Data) & 6,0 & 3,3 & 14,2 & 2,7 & 10,9 & $55 \%$ & $23 \%$ \\
Original & 6,2 & 3,8 & 14,2 & 2,4 & 10,4 & $62 \%$ & $27 \%$ \\
Yearly optimum & 6,6 & 3,9 & 14,2 & 2,6 & 10,2 & $60 \%$ & $28 \%$ \\
Canopy (SE \& SW) & 6,7 & 4,0 & 14,2 & 2,7 & 10,2 & $60 \%$ & $28 \%$ \\
Canopy (SE) & 3,6 & 2,9 & 14,2 & 0,7 & 11,3 & $79 \%$ & $20 \%$ \\
Canopy (SW) & 3,1 & 2,3 & 14,2 & 0,7 & 11,9 & $76 \%$ & $16 \%$ \\
Façade (SE \& SW) & 5,0 & 3,6 & 14,2 & 1,5 & 10,6 & $71 \%$ & $25 \%$ \\
\hline
\end{tabular}




\begin{tabular}{cccccccc}
\hline Façade (SE) & 2,5 & 2,2 & 14,2 & 0,4 & 12,0 & $86 \%$ & $15 \%$ \\
Façade (SW) & 2,4 & 1,9 & 14,2 & 0,6 & 12,3 & $77 \%$ & $13 \%$ \\
Canopy \& Façade & 6,1 & 3,9 & 14,2 & 2,2 & 10,3 & $64 \%$ & $28 \%$ \\
(SE) \& (SW) & & & & & & & \\
\hline
\end{tabular}

${ }^{1}$ All energies are expressed in MWh; ${ }^{2}$ SCD - Self Consumption Degree; ${ }^{3}$ SSD - Self Sufficiency Degree.

\subsubsection{Economic analysis}

The current regulation in Spain follows a net-billing scheme, so the economic profit for a PVSC comes from two items: the energy self-consumed, that is not bought from the grid, and it is valued at retail prices, and the surplus energy that is fed to the grid and it is valuated at a price slightly lower than the pool market electricity price. These prices are available from the Spanish TSO Red Eléctrica in the web portal ESIOS [38]. With the hourly energies and prices, the balances are calculated and are summarized in the yearly results shown in Table 5.

Table 5. Yearly economic profit for different PVSC configurations and tariffs 2.0A, 2.0DHA and new 2.0TD tariff. Surplus compensation is also shown for reference.

\begin{tabular}{ccccc}
\hline & $\begin{array}{c}\text { Surplus } \\
\text { Compensation }\end{array}$ & Profit 2.0A & Profit \\
\hline 2.0DHA & Profit 2.0TD \\
\hline Original (Real Data) & $84,56 €$ & $393,41 €$ & $352,49 €$ & $456,01 €$ \\
Original & $76,21 €$ & $436,02 €$ & $354,73 €$ & $498,73 €$ \\
Yearly optimum & $84,10 €$ & $457,39 €$ & $386,05 €$ & $521,50 €$ \\
Canopy (SE \& SW) & $83,02 €$ & $461,93 €$ & $410,94 €$ & $536,18 €$ \\
Façade (SE \& SW) & $47,42 €$ & $386,76 €$ & $332,72 €$ & $435,12 €$ \\
Canopy (SE) \& Façade (SW) & $68,99 €$ & $435,93 €$ & $391,11 €$ & $505,05 €$ \\
\hline
\end{tabular}

These results are shown in Table 6 relative to the original (simulated) configuration. The best economic performer is the configuration based on canopies on southeast and southwest façades. Considering that the installed power for this configuration is $20 \%$ higher than the original and the yearly optimum and that the yearly produced energy, the profit is the best for this configuration.

Table 6. Variations in economic profit for different configurations and tariffs with respect to the original configuration.

\begin{tabular}{cccc}
\hline Configuration & $\Delta$ 2.0A & $\Delta$ 2.0DHA & $\Delta$ 2.0TD \\
\hline Original (Real Data) & $-9 \%$ & $-8 \%$ & $-10 \%$ \\
Original & $0 \%$ & $0 \%$ & $0 \%$ \\
Yearly optimum & $5 \%$ & $8 \%$ & $5 \%$ \\
Canopy (SE \& SW) & $6 \%$ & $11 \%$ & $7 \%$ \\
Façade (SE \& SW) & $-11 \%$ & $-7 \%$ & $-10 \%$ \\
Canopy (SE) \& Façade (SW) & $1 \%$ & $2 \%$ & $-1 \%$ \\
\hline
\end{tabular}

Our study incorporates TROI as the first economic measure. TROI is one of the most widely used methods for comparing the benefits of a programme with the same costs per unit, per person or aggregated for the programme as a whole.

We take TROI because it is a cost-benefit oriented economic method [40]. Still, it is also used to calculate Return on Investment (ROI), i.e. how much is produced by how much is invested.

Table 7. Time of return of investment in years for the different PVSC configurations and tariffs. 


\begin{tabular}{ccccc}
\hline Configuration & Cost & TROI 2.0A & TROI 2.0DHA & TROI 2.0TD \\
\hline Original (Real Data) & $6.148,00 €$ & 15,6 & 17,4 & 13,5 \\
Original & $6.148,00 €$ & 14,2 & 16,1 & 12,1 \\
Yearly optimum & $6.148,00 €$ & 13,6 & 14,9 & 11,5 \\
Canopy (SE \& SW) & $8.159,00 €$ & 17,8 & 19,3 & 15,0 \\
Façade (SE \& SW) & $7.919,00 €$ & 20,6 & 22,2 & 17,3 \\
Canopy (SE) \& Façade (SW) & $8.039,00 €$ & 18,4 & 20,6 & 15,9 \\
\hline
\end{tabular}

One way of incorporating the economic feasibility study is to study the net present value (NPV) as a more robust measure of economic calculation. By NPV, we mean the discounted value of all cash flows at the source at a discount rate that matches the cost of capital. For our study, what we do is to value at a given point in time the unrealized cost of the investment project (i.e. the initial outlay) and the expected higher satisfaction in the future (i.e. the expected cash flows). We apply a process of choosing the current point in time as the point at which both the payout and the cash flows should be valued, so we apply a discounting process. To apply this discounting process, we incorporate the discount rate, which is the opportunity cost of the project, known as the cost of capital.

These calculations are performed considering a 25 lifespan of the PVSC installation, with a $0.8 \%$ yearly degradation rate and an inverter replacement on the $13^{\text {th }}$ year (also valid for IIR and LCOE calculations). The discount rate is selected as $1 \%$. As can be seen in Table 8, the project is profitable in economic terms as it has positive NPV except for the PVSC configurations and tariffs:

- Canopy (SE \& SW) and 2.0DHA

- Façade (SE \& SW) and 2.0A in addition to 2.0DHA

- Canopy (SE) \& Façade (SW) and 2.0DHA

Table 8. Net Present Value for the different PVSC configurations and tariffs.

\begin{tabular}{ccccc}
\hline Configuration & Cost & NPV 2.0A* & NPV 2.0DHA & NPV 2.0TD* \\
\hline Original (Real Data) & $6.148,00 €$ & $1.063,05 €$ & $239,85 €$ & $2.322,32 €$ \\
Original & $6.148,00 €$ & $1.835,79 €$ & $838,96 €$ & $3.384,91 €$ \\
Yearly optimum & $6.148,00 €$ & $2.244,99 €$ & $1.461,05 €$ & $3.943,79 €$ \\
Canopy (SE \& SW) & $8.159,00 €$ & $360,98 €$ & $-353,63 €$ & $2.083,69 €$ \\
Façade (SE \& SW) & $7.919,00 €$ & $-895,71 €$ & $-1.455,27 €$ & $578,11 €$ \\
Canopy (SE) \& Façade (SW) & $8.039,00 €$ & $27,41 €$ & $-874,25 €$ & $1.417,76 €$ \\
\hline
\end{tabular}

Another criterion to make our study more robust is the so-called internal return ratio or IRR. It is defined as the discount rate that equals the NPV of the investment to 0 . This is a study of relative profitability to provide a final argument for the TROI and NPV.

IRR provides us with one of the most widespread measures of profitability as it provides a more intuitive idea of the adequacy to what is expected from an investment, as it is a value that we can easily compare with interest rates, which is one of the main components that determine the cost of capital in a given project. In Table 9 the results are presented and in an outstanding way the IRR with the new tariff 2.0TD is 2 points higher than with the current 2.0A. 
Table 9. Internal Rate of Return for the different PVSC configurations and tariffs.

\begin{tabular}{ccccc}
\hline Configuration & Cost & IRR 2.0A* & IRR 2.0DHA & IRR 2.0TD* \\
\hline Original (Real Data) & $6.148,00 €$ & $2 \%$ & $1 \%$ & $4 \%$ \\
Original & $6.148,00 €$ & $3 \%$ & $2 \%$ & $5 \%$ \\
Yearly optimum & $6.148,00 €$ & $4 \%$ & $3 \%$ & $6 \%$ \\
Canopy (SE \& SW) & $8.159,00 €$ & $1 \%$ & $1 \%$ & $3 \%$ \\
Façade (SE \& SW) & $7.919,00 €$ & $0 \%$ & $-1 \%$ & $2 \%$ \\
Canopy (SE) \& Façade (SW) & $8.039,00 €$ & $1 \%$ & $0 \%$ & $2 \%$ \\
\hline
\end{tabular}

The Levelized Cost of Electricity (LCOE) is a metric that informs about the cost of electricity independent of the technology used for generation. From the costs of the different installations, the LCOE will be calculated following the procedure as exposed in [41] and expressed in equation (3). For the calculations, The results for the different configurations are presented in Table 10.

$$
L C O E=\frac{\sum_{t=0}^{T} C_{t} /(1+r)^{t}}{\sum_{t=0}^{T} E_{t} /(1+r)^{t}}
$$

where $C_{t}$ are the costs, $E_{t}$ the energy produced and $r$ the discount rate.

Table 10. Levelized Cost of electricity for the different PVSC configurations.

\begin{tabular}{ccc}
\hline Configuration & Cost & LCOE (€/kWh) \\
\hline Original (Real Data) & $6.148,00 €$ & 0,0597 \\
Original & $6.148,00 €$ & 0,0578 \\
Yearly optimum & $6.148,00 €$ & 0,0545 \\
Canopy (SE \& SW) & $8.159,00 €$ & 0,0712 \\
Façade (SE \& SW) & $7.919,00 €$ & 0,0920 \\
Canopy (SE) \& Façade (SW) & $8.039,00 €$ & 0,0770 \\
\hline
\end{tabular}

For a proper comparison, the averaged and median values of the residential tariffs for the period under study are calculated and presented in Table 11. The weighted average is calculated using the real data from the residential PVSC under study. The LCOE for all configurations is under mean prices of tariff 2.0A and the new 2.0TD. The price for tariff 2.0DHA is low but this is a two-period tariff and the PVSC produces mostly in the peakrate period. For the new 2.0TD tariff is a similar situation because this is a three-period tariff, and the peak-rate is higher than 2.0DHA and 2.0A, being the lowest rate at night and at weekends. The price at which the surplus is compensated is somewhat low due to the low electricity prices in 2020 due to the pandemic of COVID. With the increase in PV generation in Spain is foreseeable a scenario of low pool market prices at the periods where PV is producing most, reducing the incomes from surplus compensation.

Table 11. Retail prices for electricity in year 2020.

\begin{tabular}{ccc}
\hline Tariff & Weighted Average price $(€ / \mathbf{k W h})$ & Median value price $(€ / \mathbf{k W h})$ \\
\hline $2.0 \mathrm{~A}$ & 0,1034 & 0,09450 \\
$2.0 \mathrm{DHA}$ & 0,07308 & 0,06143 \\
$2.0 \mathrm{TD}^{1}$ & 0,09600 & 0,07413 \\
surplus $^{1}$ & 0,03113 & 0,03433 \\
\hline
\end{tabular}

${ }^{1}$ Estimated.

\subsection{Industrial PVSC}


Considering that this PVSC is in operation since September 2020, there is no data available for an analysis such as complete as for the residential example. Figure 6 shows the heatmaps for the hourly consumed energy 6(a), PV-produced 6(b) and imported from the grid 6(c). It can be appreciated the good fitting between the factory peak load before noon and the PV production. Also, in Figure 6(c) can be seen near zero consumption periods due to the PVSC. The horizontal band in the center of all figures correspond to the period of unavailable data due to the recent construction of this PVSC.

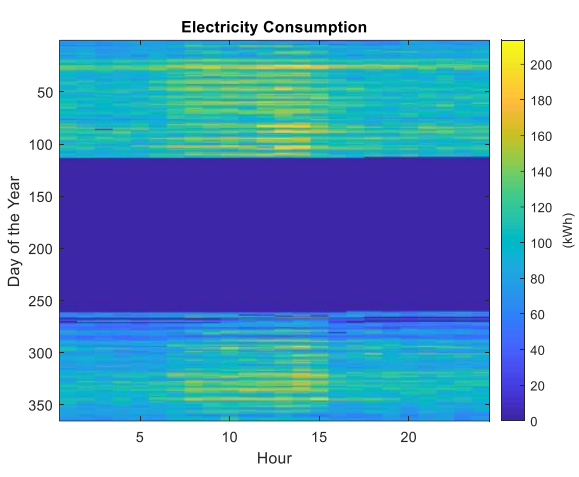

(a)

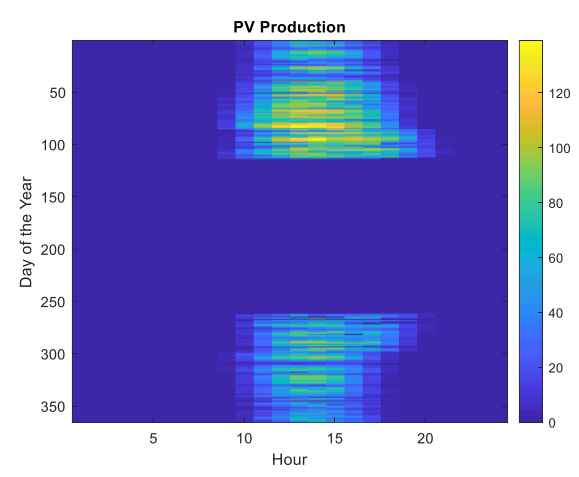

(b)

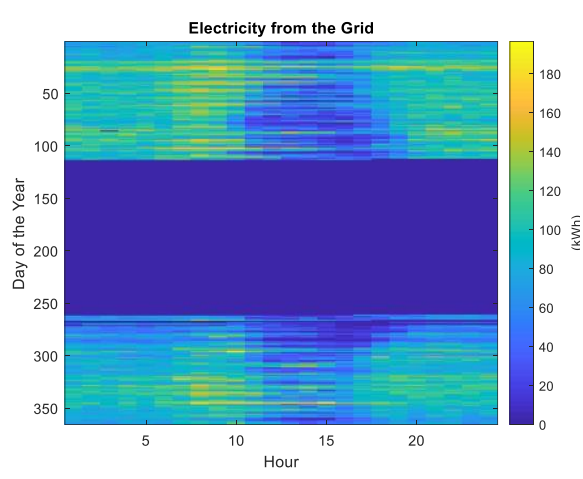

(c)

Figure 6. Heatmaps for industrial PVSC plant (a) Electricity consumption (b) PV Production (c) Energy imported from the grid.

The three configurations summarized in Table 2 have been simulated in PVSYST with the same modules, power optimizers and inverters. In Figure 7 the hourly production for two clear-sky days is presented. Figure 7(a) correspond to a winter day and Figure 7 (b) to a summer day. For a proper comparison, the data from the three configurations is rescaled to $169 \mathrm{~kW}$. It can be seen that due to the low inclination of the modules, the variations between the South orientation layout and the 2-orientations layout is low, but in summer the 2-orientations production profile is more rounded, with a lower peak and higher production at sunrise and sunset. The East-West configuration has a marginally better behavior in summer, but it is poor in winter.

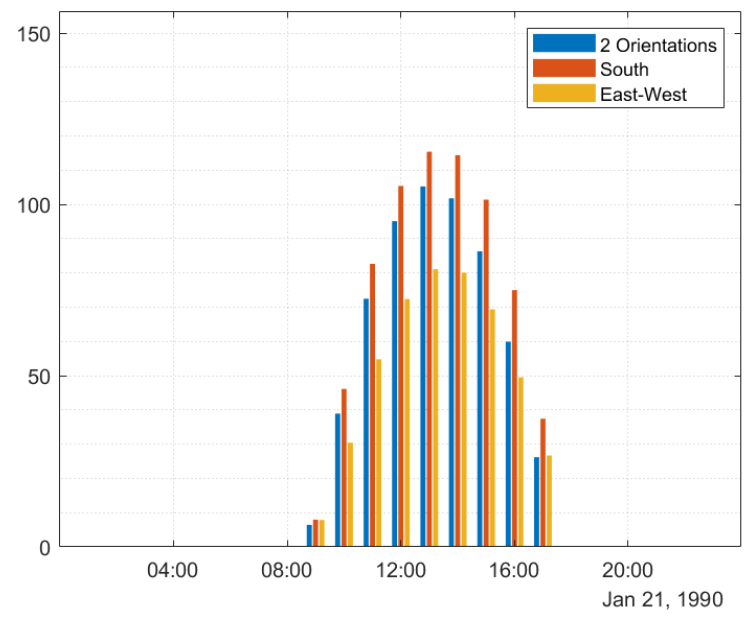

(a)

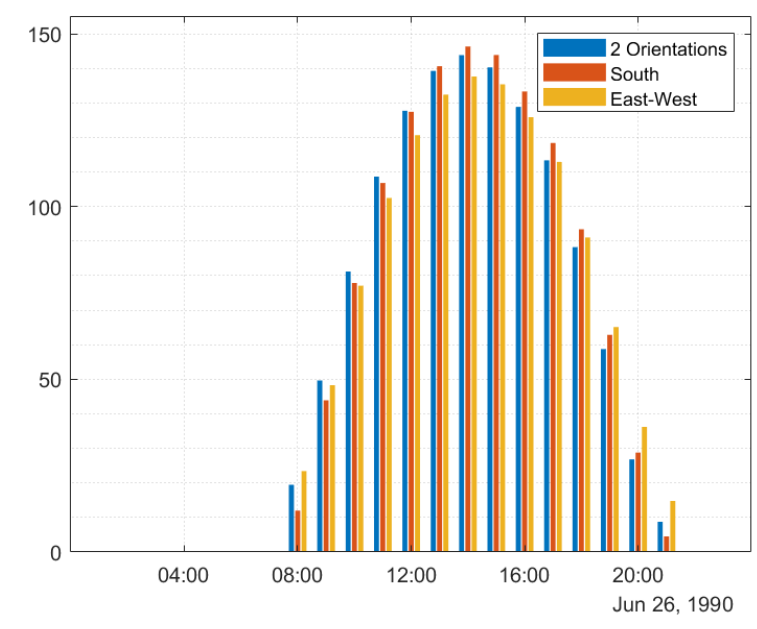

(b)

Figure 7. PV production of different configurations with the same rated power for industrial PVSC plant on representative days (a) Winter day, (b) Summer day. (1990 is the default year for PVSYST simulations). 
The behavior of the real PVSC on one day is presented in Figure 9. As can be seen, the energy consumption decreases at lunchtime, between 14:00 and 16:00. This can make the electricity consumption from the grid too low, so the inverters curtail the production. According to the Spanish regulation, if the PVSC is connected under the category without surplus, grid feeding is not allowed in any of the three electricity phases. So, if the electrical loads into the factory are not well-balanced it could result in higher PV production losses. This fact is important in favor of PVSC layouts that yield the energy with flatter and longer production profiles.

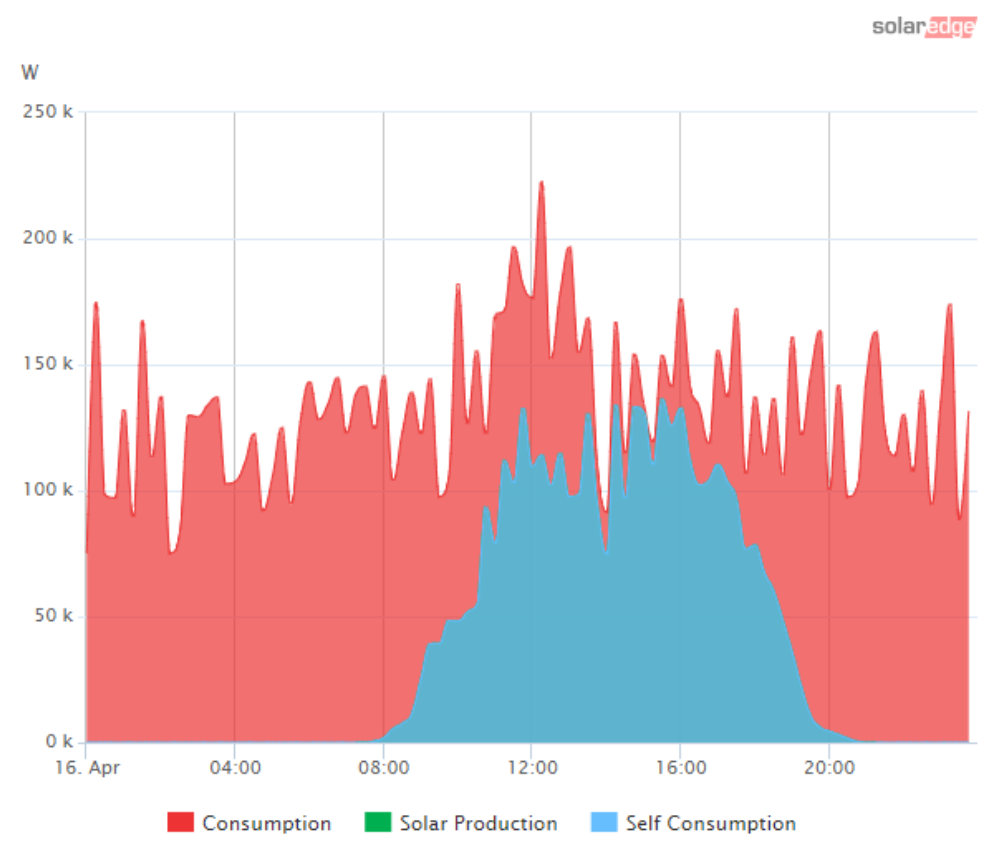

Figure 8. Screenshot of the monitoring portal showing energy consumption and production on one spring day.

\section{Discussion and conclusions}

For the residential case, it is found that the economic yield for these orientations is better than its energy yield. One reason is that using several orientations spread production more uniformly during the daytime, increasing the self-consumption share of PVproduced electricity. The other reason is found in the variable prices for the retail electricity and the surplus electricity fed into the distribution grid. With the maturity of PV sector, the actual net-billing schemes, like the current one in Spain, are more appropriate than net-metering policies since the surplus price is valuated following the prices of electricity in the wholesale market, thus signaling the periods when distributed generation is more valuable [42]. The use of these non-optimal orientations can reduce the electricity interchanged with the grid, especially the energy fed, resulting in a reduction of the energy stress on the grid [43].

The introduction of residential tariffs with higher prices in periods of high electricity consumption will add an additional profit to the Southeast orientations, which produce most electricity in the hours before noon, just in one of the two peak tariff periods. From the data in table 5, the increase in profits over the current one period tariff is calculated and ranges between $16 \%$ and $19 \%$, and around $30 \%$ over the current two period tariff.

Beside the PVSC operation, is important to remark the necessity of implementing demand side strategies. For example, in Figure 4(a) is clear the use or air conditioning 
during the night in summer, that can be shifted to the hours when PV production is high using self-produced PV electricity and providing higher economic savings.

From a wider perspective, the use of these orientations can provide an important increase in the suitable area for PV, beyond roofs [22,44]. Traditionally, other uses of PV than roofs are perceived as inefficient or uneconomic and reserved for emblematic or flagship buildings. Our study shows that even when the energy performance is lower than traditional orientations, the economic performance is not so far from them. Considering that PV modules can replace building materials, the overall economic balance can be positive. In addition, the use of PV as shading elements as canopies can be used by architects to improve the user's comfort and the energy performance of the building by reducing cooling needs while increasing the energy production. These facts are suitable with the BIPV concept and can help the expansion of this sector.

For the industrial PVSC, it is found that non-optimal PV orientations can be an advantage over traditional south facing orientations optimal for yearly energy production. The main advantages found can be summarized as follows:

- Higher installed power due to more efficient use of available space in roofs.

- Higher energy production in the available space.

- Good economic yield by adaptation to variable electricity tariffs and load patterns of industry.

- Lower curtailment of PV production or energy fed into the distribution grid.

- More ordered PV Layout, easing installation, operation and maintenance and overall safety for workers.

Future directions of this work are a systematic research of different orientations for representative residential, commercial, and industrial users, and the development of a methodology for optimal sizing of PV installations.

The performance of several non-optimal orientations has been studied for residential and industrial cases. It has been found that the economic performance of this orientations is acceptable under the net-billing self-consumption scheme in Spain. An additional advantage for these orientations is found in the new residential tariffs, with a peak period before noon that increases savings of non-optimal PVSC installations over the maximum energy orientation. This fair energy and economic performance can promote a wider use of BIPV.

For the industrial sector, several advantages have been identified in the operation of the case under study that allows a higher energy production, better economic return, and less curtailment or energy fed into the distribution grid.

With the current outlook of an increased deployment of zero-marginal-cost generation sources as PV, wholesale market electricity prices are expected to decline at noon while at the same time retail prices are high due to the peak of consumption, the use of non-optimal orientations can be highly beneficial.

Complementarily, these results help us to demystify general rules of photovoltaic installations, such as: "The solar panels have to be oriented towards the South" and "The panels must be inclined according to the latitude of the site". The remarkable performance of systems with non-optimal orientations allows further flexibility in the installation of PVSC in residences and buildings, coupling without aesthetically distorting the structure 
and obtaining an acceptable economic benefit with an economic yield that varies slightly compared to installations with optimal orientations.

Author Contributions: Conceptualization, E.S. and A.J.O.; methodology, E.S. and A.J.O.; software, E.S.; investigation, E.S., A.J.O. and J.P-D.; resources, E.S and A.S.; data curation, E.S.; writing-original draft preparation, E.S, A.J.O. and J.P-D.; writing-review and editing, E.S., A.J.O., A.S., R.G., and J.P-D.; visualization, E.S.; supervision, R.G.; project administration, E.S. and R.G.; funding acquisition, R.G.

All authors have read and agreed to the published version of the manuscript.

Funding: This research was funded by "Fundación Memoria de D. Samuel Solórzano Barruso", grant number FS/21-2019.

Data Availability Statement: Restrictions apply to the availability of these data.

Acknowledgments: The authors wish to thank Roberto Vicente Babiano for sharing the data from his home PVSC and Marcial Castro S.L. for sharing the data from its new factory PVSC.

Conflicts of Interest: One of the authors (A. S.) redacted the engineering project and was responsible of the works direction for the PVSC in the industrial plant. E.S. collaborate in this project with the analysis of the different configurations and the PV design and calculations for the final layout. There is no other conflict of interest.

\section{References}

1. Shahsavari, A.; Akbari, M. Potential of solar energy in developing countries for reducing energy-related emissions. Renew. Sustain. Energy Rev. 2018, 90, 275-291.

2. Sharif, A.; Meo, M.S.; Chowdhury, M.A.F.; Sohag, K. Role of solar energy in reducing ecological footprints: An empirical analysis. J. Clean. Prod. 2021, 292, 126028, doi:10.1016/j.jclepro.2021.126028.

3. DNV GL Energy transition outlook 2018 power supply and use; 2018;

4. IEA Global Energy Review 2021 ; Paris, 2021;

5. Singh, G.K. Solar power generation by PV (photovoltaic) technology: A review. Energy 2013, 53, 1-13.

6. IRENA Solar Energy Data Available online: https://irena.org/solar (accessed on Apr 12, 2021).

7. SolarPower Europe EU solar boom: over 100\% solar market increase in 2019 - SolarPower Europe Available online: https://www.solarpowereurope.org/eu-solar-boom-over-100-solar-market-increase-in-2019/ (accessed on Apr 12, 2021).

8. SolarPower Europe EU Market Outlook for Solar Power 2019-2023 - SolarPower Europe Available online: https://www.solarpowereurope.org/eu-market-outlook-for-solar-power-2019-2023/ (accessed on Apr 12, 2021).

9. Cucchiella, F.; D'Adamo, I. Feasibility study of developing photovoltaic power projects in Italy: An integrated approach. Renew. Sustain. Energy Rev. 2012, 16, 1562-1576.

10. Fthenakis, V.; Mason, J.E.; Zweibel, K. The technical, geographical, and economic feasibility for solar energy to supply the energy needs of the US. Energy Policy 2009, 37, 387-399, doi:10.1016/j.enpol.2008.08.011.

11. Nematollahi, O.; Kim, K.C. A feasibility study of solar energy in South Korea. Renew. Sustain. Energy Rev. 2017, 77, 566-579.

12. Shafiullah, G.M.; Amanullah, M.T.O.; Shawkat Ali, A.B.M.; Jarvis, D.; Wolfs, P. Prospects of renewable energy - a feasibility study in the Australian context. Renew. Energy 2012, 39, 183-197, doi:10.1016/j.renene.2011.08.016.

13. Iea-pvps, R. Trends 2013 in PV applications; 2013;

14. Madeti, S.R.; Singh, S.N. Online fault detection and the economic analysis of grid-connected photovoltaic systems. Energy 2017, 134, 121-135, doi:10.1016/j.energy.2017.06.005.

15. Kosorić, V.; Huang, H.; Tablada, A.; Lau, S.K.; Tan, H.T.W. Survey on the social acceptance of the productive façade concept integrating photovoltaic and farming systems in high-rise public housing blocks in Singapore. Renew. Sustain. Energy Rev. 2019, 111, 197-214, doi:10.1016/j.rser.2019.04.056. 
16. Strazzera, E.; Statzu, V. Fostering photovoltaic technologies in Mediterranean cities: Consumers' demand and social acceptance. Renew. Energy 2017, 102, 361-371, doi:10.1016/j.renene.2016.10.056.

17. Green, M.A. Third generation photovoltaics: Solar cells for 2020 and beyond. In Proceedings of the Physica E: LowDimensional Systems and Nanostructures; North-Holland, 2002; Vol. 14, pp. 65-70.

18. Agathokleous, R.A.; Kalogirou, S.A. Status, barriers and perspectives of building integrated photovoltaic systems. Energy 2020, 191, 116471, doi:10.1016/j.energy.2019.116471.

19. Shukla, A.K.; Sudhakar, K.; Baredar, P. A comprehensive review on design of building integrated photovoltaic system. Energy Build. 2016, 128, 99-110.

20. Raugei, M.; Frankl, P. Life cycle impacts and costs of photovoltaic systems: Current state of the art and future outlooks. Energy 2009, 34, 392-399, doi:10.1016/j.energy.2009.01.001.

21. Fath, K.; Stengel, J.; Sprenger, W.; Wilson, H.R.; Schultmann, F.; Kuhn, T.E. A method for predicting the economic potential of (building-integrated) photovoltaics in urban areas based on hourly Radiance simulations. Sol. Energy 2015, 116, 357-370, doi:10.1016/j.solener.2015.03.023.

Redweik, P.; Catita, C.; Brito, M. Solar energy potential on roofs and facades in an urban landscape. Sol. Energy 2013, 97, 332341, doi:10.1016/j.solener.2013.08.036.

23. Dávi, G.A.; Caamaño-Martín, E.; Rüther, R.; Solano, J. Energy performance evaluation of a net plus-energy residential building with grid-connected photovoltaic system in Brazil. Energy Build. 2016, 120, 19-29, doi:10.1016/j.enbuild.2016.03.058.

24. Olson, A.; Jones, R. Chasing Grid Parity: Understanding the Dynamic Value of Renewable Energy. Electr. J. 2012, 25, 17-27, doi:10.1016/j.tej.2012.03.001.

25. Almeida Dávi, G.; López de Asiain, J.; Solano, J.; Caamaño-Martín, E.; Bedoya, C. Energy Refurbishment of an Office Building with Hybrid Photovoltaic System and Demand-Side Management. Energies 2017, 10, 1117, doi:10.3390/en10081117.

26. Briano, J.I.; Pardo, I.; Denoyes, C. PV Grid Parity Monitor: Commercial Sector 5th Issue; 2018;

27. Luthander, R.; Widén, J.; Nilsson, D.; Palm, J. Photovoltaic self-consumption in buildings: A review. Appl. Energy 2015, 142, 80-94.

28. IEA PVPS TRENDS 2013 IN PHOTOVOLTAIC APPLICATIONS; IEA-PVPS T1-23:2013.; 2013; ISBN 9783906042145.

29. Ordóñez Mendieta, Á.J.; Hernández, E.S. Analysis of PV Self-Consumption in Educational and Office Buildings in Spain. Sustainability 2021, 13, 1662, doi:10.3390/su13041662.

30. Yamamoto, Y. Pricing electricity from residential photovoltaic systems: A comparison of feed-in tariffs, net metering, and net purchase and sale. Sol. Energy 2012, 86, 2678-2685, doi:10.1016/j.solener.2012.06.001.

31. Government of Spain Royal Decree 244/2019; BOE: Spain, 2019;

32. Government of Spain Royal Decree-Law 15/2018; BOE, Núm. 242: Spain, 2018;

33. Roldán Fernández, J.M.; Burgos Payán, M.; Riquelme Santos, J.M. Profitability of household photovoltaic self-consumption in Spain. J. Clean. Prod. 2021, 279, 123439.

34. Gholami, H.; Røstvik, H.N. Economic analysis of BIPV systems as a building envelope material for building skins in Europe. Energy 2020, 204, 117931, doi:10.1016/j.energy.2020.117931.

35. Sánchez, E.; Izard, J. Performance of photovoltaics in non-optimal orientations: An experimental study. Energy Build. 2015, 87, doi:10.1016/j.enbuild.2014.11.035.

36. Evola, G.; Margani, G. Renovation of apartment blocks with BIPV: Energy and economic evaluation in temperate climate. Energy Build. 2016, 130, 794-810, doi:10.1016/j.enbuild.2016.08.085.

37. Fogl, M.; Moudrý, V. Influence of vegetation canopies on solar potential in urban environments. Appl. Geogr. 2016, 66, 73-80, doi:10.1016/j.apgeog.2015.11.011.

38. Red Eléctrica de España (REE) esios - Autoconsumo Available online: https://www.esios.ree.es/es/analisis/1739?vis=1\&start_date=16-03-2021T00\%3A00\&end_date=16-03-

2021T23\%3A00\&compare_start_date=15-03-2021T00\%3A00\&groupby=hour\&compare_indicators=1013,1014,1015 (accessed 
on Dec 3, 2020).

39. Comisión Nacional de los Mercados y la Competencia Memoria justificativa de la circular de la Comisión Nacional de los Mercados y la Competencia por la que se establece la metodología para el cálculo de los peajes de transporte y distribución de electricidad.; 2020;

40. Rosenzweig, W. Double Bottom Line Project Report : Assessing Social Impact In double bottom line project report : assessing social impact in double bottom line ventures. Cent. Responsible Business. Work. Pap. Ser. 2004.

41. Branker, K.; Pathak, M.J.M.; Pearce, J.M. A review of solar photovoltaic levelized cost of electricity. Renew. Sustain. Energy Rev. 2011.

42. Brown, P.R.; O'Sullivan, F.M. Shaping photovoltaic array output to align with changing wholesale electricity price profiles. Appl. Energy 2019, 256, 113734, doi:10.1016/j.apenergy.2019.113734.

43. Thebault, M.; Gaillard, L. Optimization of the integration of photovoltaic systems on buildings for self-consumption - Case study in France. City Environ. Interact. 2021, 100057, doi:10.1016/j.cacint.2021.100057.

44. Brito, M.C.; Freitas, S.; Guimarães, S.; Catita, C.; Redweik, P. The importance of facades for the solar PV potential of a Mediterranean city using LiDAR data. Renew. Energy 2017, 111, 85-94, doi:10.1016/j.renene.2017.03.085. 